Case report

\title{
Not functioning adrenocortical carcinoma from diagnosis to management: a case report
}

\author{
Behnaz Bazrafshan ${ }^{1}$, Payam Sarmadi ${ }^{2}$, Mohammad Reza Hashempour ${ }^{3^{*}}$, Masoomeh Rostami ${ }^{4}$, Abdolreza \\ Fazel $^{5}$, Akram Sanagoo ${ }^{6}$, Leila Jouybari ${ }^{6}$, Seyed Payam Shirangi ${ }^{1}$
}

(Received: 1 Mar 2016; Accepted: 16 May 2016)

\begin{abstract}
Adrenal gland cysts are rare indications of adrenal diseases, which are commonly asymptomatic. In radiological studies, these cysts, known as incidentalomas, are often detected by coincidence accounting for $6 \%$ of the population. Adrenal incidentalomas are commonly detected, and autonomous cortisol hypersecretion is the most prevalent abnormality associated with these masses. Since this complication is recurrent, it requires intermittent morphological and hormonal evaluation for several years. In this paper, we aimed to present the case of a 52-year-old woman with complaints of vague abdominal pain. After laparotomy, the tumor was removed, and umbilical herniorrhaphy was performed on the patient. Laparoscopic adrenalectomy is the first-line surgical treatment for this type of incidentaloma. Ultrasonography revealed an echogenic mass (diameter: $4 \mathrm{~cm}$ ) in the left adrenal gland of the patient, which was not associated with hernia. In addition, CT-scan showed that the adrenal lesion was hypodense and heterogeneous (diameters: $81 * 53 \mathrm{~mm}$ ) with sharp, irregular borders.
\end{abstract}

Keywords: Adrenal gland cysts, Incidentaloma, Laparoscopic adrenalectomy

\section{Introduction}

Adrenal gland cysts are rare indications of adrenal diseases, which are commonly asymptomatic (1-3). Adrenal tumors with sudden onset require complex management strategies (diameter: $\geq 1$ $\mathrm{cm})$. In radiological studies, these cysts, known as incidentalomas, are often detected by coincidence accounting for $6 \%$ of the population (4).

With recent advancement in paraclinical facilities, such as ultrasound and CT-scan, identification of many adrenal cysts has become easier through various diagnostic procedures (1-3). Androgenproducing adrenal tumors are relatively rare. These tumors may appear as benign (adenoma) or malignant (carcinoma) cases. According to the literature, 50\% of androgen-producing adrenal masses are reported to be benign, while the others are diagnosed as malignant (5).

Androgen-producing adenomas are rarely observed, and only 50 cases have been reported in the medical literature so far. For instance, these masses often appear before menopause in women, along with symptoms such as severe hirsutism, voice mutation, and amenorrhea. Furthermore, $80 \%$ of the female patients with androgen-producing adenomas develop clitomegaly $(6,7)$.

Adrenal adenomas may be functional or nonfunctional. Statistics show that $85 \%$ of these masses are non-functional, while only $15 \%$ are functional with hormonal secretion (8).

Adrenocortical adenomas are detected in $15 \%$ of

\footnotetext{
${ }^{1}$ Medical Cellular and Molecular Research Center, Golestan University of Medical Sciences, Gorgan, Iran

${ }^{2}$ Family Medicine Department, Faculty of Medicine, Isfahan University of Medical Sciences, Isfahan, Iran

${ }^{3,{ }^{*}}$ Corresponding author: Resident of Surgery, Students Research Committee, Department of Surgery, 5-Azar Teaching Hospital, Golestan University of Medical Sciences, Gorgan, Iran. Email: hashempourm@yahoo.com

${ }^{4}$ Department of Parasitology and Mycology, School of Medicine, Golestan University of Medical Sciences, Gorgan, Iran

${ }^{5}$ Surgeon, Department of Surgery, 5-Azar Teaching Hospital, Golestan University of Medical Sciences, Gorgan, Iran

${ }^{6}$ Nursing Research Center, Department of Nursing, Golestan University of Medical Sciences, Gorgan, Iran 
the patients presenting with adrenal masses. These benign tumors secret cortisol and have a diameter of smaller than $4 \mathrm{~cm}$. A rare finding in this regard is large adenoma, which has been shown to cause the Cushing's syndrome (9).

\section{Case Presentation}

A 52-year-old woman referred to our clinical center with complaints of vague abdominal pain. She had a history of laparoscopic cholecystectomy (six years ago). A few months after the surgery, the patient noticed a painless bulging in her abdomen, which was diagnosed as umbilical hernia. Recently, she experienced vague abdominal pain and underwent abdominal ultrasonography to assess the umbilical hernia.

Ultrasonography of the patient revealed an echogenic mass (diameter: $4 \mathrm{~cm}$ ) in the left adrenal gland, which had not arisen from the hernia. The patient presented with no other signs or symptoms, such as flushing and hyperhidrosis. CT-scan was performed, and the results showed the adrenal lesion to be hypodense and heterogeneous (diameters: $81 * 53 \mathrm{~mm}$ ) with sharp, irregular borders (Figure 1). Moreover, the cyst had 65\% absolute percentage washout in 10 minutes, which

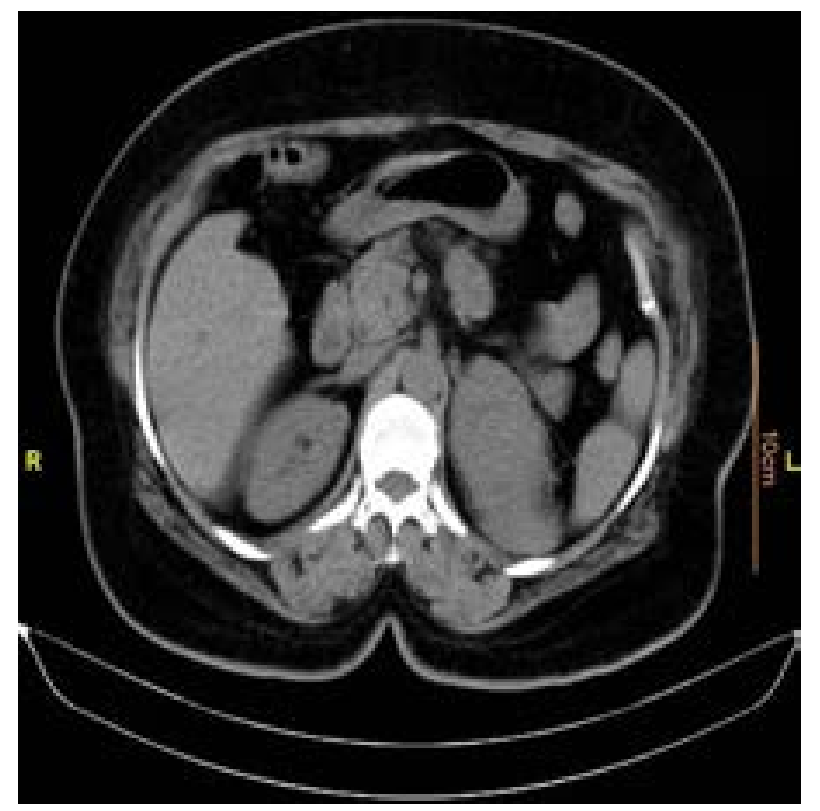

Figure 1. Abdominal CT-scan of patient is a characteristic of benign adrenal masses.

Routine laboratory tests of the patient were normal, with the exception of thyroid-stimulating hormone $(7.12 \mathrm{mIU} / \mathrm{ml})$. The patient had a history of hypothyroidism and received treatment with levothyroxine. In addition, 24-hour urine analysis and endocrinology tests were carried out. In the 24hour urine sample, vanillylmandelic acid was 5.6 $\mathrm{mg} / 24$ hours (normal range: $<13.6$ ), metanephrine was $195 \mu \mathrm{g} / 24$ hours (normal range: <350), normetanephrine was $843 \mu \mathrm{g} / 24$ hours (normal range: $<600$ ), and 5-OH-indole acetic acid was 4.8 $\mathrm{mg} / 24$ hours (normal range: $<15$ ).

Urine free cortisol was $191 \mu \mathrm{g} / 24$ hours (normal range: 50-190). Considering the age of the patient, dehydroepiandrosterone level was within the normal range ( $139 \mu \mathrm{g} / \mathrm{dL}$, normal range: $33-212 \mu \mathrm{g} /$ dL). Moreover, upright serum aldosterone was 382 $\rho \mathrm{g} / \mathrm{ml}$ higher than the normal range $(40-310 \rho \mathrm{g} / \mathrm{ml})$, while plasma rennin activity was $3.9 \mathrm{IU} / \mathrm{ml}$ (normal range: 0.06-4.69 IU/ml).

In the next stage, the patient underwent laparotomy. After the removal of the tumor, umbilical herniorrhaphy was carried out.

\section{Discussion}

Adrenal gland was first described as an identifiable structure by Bartolomeo Eustachio in 1563. Due to its small size, this organ is anatomically ambiguous. As such, clinical explanation of adrenal deficiency was unclear before the mid- $19^{\text {th }}$ century.

Adrenal cysts are relatively rare with complex diagnoses (1). Most adrenal cysts are detected following non-specific abdominal pain, ultrasound, CT-scan or autopsies (10). However, incidentally discovered adrenal masses have various differential diagnoses, including adenoma, myelolipoma, lipoma, cyst, pheochromocytoma, primary or metastatic cancer, hyperplasia, and tuberculosis (11). Adrenal cysts are often unilateral, and the prevalence has been reported to be twice higher among women $(12,13)$. Adrenal cysts are categorized into three groups of epithelial, parasitic, and vascular.

Vascular cysts are more common than other types of adrenal masses and are divided into two subgroups 
of endothelial and hemorrhagic (pseudocysts). Endothelial cysts account for approximately $50 \%$ of all cases of adrenal cysts, followed by pseudocysts with the prevalence rate of $40 \%$ (10). Incidence of epithelial and parasitic cysts has been estimated at $7 \%$ and $9 \%$, respectively. Moreover, some of these cysts are of neoplastic origin, arising from necrotic tissue remnants (14). According to the literature, pseudocysts constitute $80 \%$ of all the cases of cystic adrenal masses $(3,15,16)$.

With regard to pseudocysts, it is noteworthy that these masses are associated with the possibility of intracystic hemorrhage (with or without known etiology), which could pose significant risk to the health of the patients, leading to the need for surgical operation $(1,3)$.

Adrenocorticotropichormone (ACTH) stimulation test is used for the detection of adrenal insufficiency and congenital adrenal hyperplasia $(\mathrm{CAH}) . \mathrm{CAH}$ syndrome is the deficiency of 21-hydroxylase or 11beta hydroxylase, in which the stimulation of ACTH directs steroidogenesis to precursors. Normal range of 17-hydroxyprogesterone in healthy individuals is $10-100 \mathrm{nmol} / \mathrm{L}$, while the normal range of cortisol concentration is $386.26-689.75 \mathrm{mmol} / \mathrm{L}$.

In patients with major depression, unusual response to ACTH stimulation test has been reported (17). On the other hand, deficient cortisol production has been observed in patients with obstructive sleep apnea, significant alcohol consumption, and obesity (18-21). Cortisol response to ACTH stimulation occurs with ACTH-independent CS, also known as ACTH-independent macronodular adrenal hyperplasia.

Considering the symptomatic laparoscopic cholecystectomy and umbilical hernia caused by the previous surgery, patients with symptomatic gallstones are candidates for surgical operation. However, if they do not receive timely treatment, they might experience occasional pain, resulting in the detection of an incidentaloma for adrenocortical adenoma.

With respect to effective laboratory methods for the diagnosis of adrenal pseudocysts, various studies have denoted the lack of diagnostic value in procedures such as ultrasound and CT-scan. In other words, identification of adrenal cysts with differential diagnoses (e.g., kidney, liver, and gallbladder masses) is complicated. Therefore, it is recommended that future studies investigate the efficacy of other approaches (e.g., MRI and urography) in the diagnosis of the patients (3).

On the other hand, findings of Gierke et al. indicated that these masses are normally asymptomatic, and few patients have complaints of vague pain in the sides of the body (11). In the present case, the patient had occasional complaints of vague abdominal pain. Since there was the possibility of intracystic hemorrhage, which might cause anemia, the patient underwent surgery immediately after diagnosis. Today, surgical operation for such patients involves laparoscopic procedures unless laparoscopy is unable to control active intracystic hemorrhage.

\section{Conclusion}

Considering their differential diagnoses, adrenal cysts (renal, hepatic and gallbladder masses) have a complex diagnosis. Furthermore, intracystic hemorrhage or trauma could lead to anemia, and patients with these complications require immediate surgery. Currently, laparoscopic adrenalectomy is considered the first-line treatment in this regard.

\section{Conflict of interest}

None declared.

\section{Authors' contributions}

All the authors had authorship criteria and contributed to the first idea of the research, data collection, writing the first draft, editing the article in Persian, English translation, writing the final draft, and editing.

\section{Acknowledgements}

We gratefully acknowledge the information provided to us by the patients and their cooperation with the study. 


\section{References}

1. De Bree E, Schoretsanitis G, Melissas J, Christodoulakis M, Tsiftsis D. Cysts of the adrenal gland: diagnosis and management. Int Urol Nephrol 1998; 30(4):369-76.

2. Pradeep PV, Mishra AK, Aggarwal V, Bhargav PR, Gupta SK, Agarwal A. Adrenal cysts: an institutional experience. World J Surg 2006; 30(10):1817-20.

3. Basile G, Buffone A, Cicciarella G, di Mari P, Cirino E. Hemorrhagic adrenal pseudocyst: case report. Ann Ital Chir 2004; 75(4):487-90.

4. Young Jr WF. The incidentally discovered adrenal mass. N Engl J Med 2007; 356(6):601-10.

5. Cordera F, Grant C, van Heerden J, Thompson G, Young W. Androgen-secreting adrenal tumors. Surgery 2003; 134(6):874-80.

6. Stewart PM. Adrenal cortex. Curr Opin Endocrinol Diabetes Obesity 2000; 7(3):107-8.

7. Gabrilove JL, Seman AT, Sabet R, Mitty HA, Nicolis GL. Virilizing adrenal adenoma with studies on the steroid content of the adrenal venous effluent and are view of the literature. Endocr Rev 1981; 2(4):462-70.

8. Melmed S. Adrenal Cortex. In: Polonsky KS, Larsen PR, Kronenberg HM, editors. Williams's textbook of endocrinology. 12th ed. Philadelphia: Elsevier Health Sciences; 2011. P. 534-6.

9. Sturgeon C, Kebebew E. Laparoscopic adrenalectomy for malignancy. Surg Clini North Am 2004; 84(3):755-74.

10. Danza FM, De Marinis L, Mancini A, Valentini AL, Summaria V, Conte G, et al. Adrenal gland cysts: our experience. Minerva Chir 1993; 48(21-22):1325-30.

11. Cook DM. Adrenal mass. Endocrinol Metab Clin North Am 1997; 26(4):829-52.
12. Moreira SG Jr, Pow-Sang JM. Evaluation and management of adrenal masses. Cancer Control 2002; 9(4):326-34.

13. Devine CJ, Jordan GH, Schlossberg SM, Walsh PC, Retik $\mathrm{AB}$, Vaughan ED, et al. Campbell's Urology. 7th ed. Philadelphia: Saunders; 1992. P. 568.

14. Gaffey MJ, Mills SE, Fechner RE, Bertholf MF, Allen MS Jr. Vascular adrenal cysts, a clinicopathologic and immunohistochemical study of endothelial and hemorrhagic (pseudocystic) variants. Am J Surg Pathol 1989; 13(9):740-7.

15. Erickson LA, Lloyd RV, Hartman R, Thompson G. Cystic adrenal neoplasms. Cancer 2004; 101(7):1537-44.

16. Bellantone R, Ferrante A, Raffaelli M, Boscherini M, Lombardi CP, Crucitti F. Adrenal cystic lesions: report of 12 surgically treated cases and review of the literature. J Endocrinol Invest 1998; 21(2):109-14.

17. Amsterdam JD, Winokur A, Abelman E, Lucki I, Rickels $\mathrm{K}$. Cosyntropin (ACTH $\alpha 1-24$ ) stimulation test in depressed patients and healthy subjects. Am J Psychiatry 1983; 7:907-9.

18. Terzolo M, Bovio S, Reimondo G, Pia A, Osella G, Borretta G. Subclinical Cushing's syndrome in adrenal incidentalomas. Endocrinol Metab Clin North Am 2005; 34(2):423-39.

19. Gilbert R, Lim EM. The diagnosis of Cushing's syndrome: an endocrien society, clinical practice guideline. Clin Biochem Rev 2008; 29(3):103-6.

20. Hudgel DW, Gordon EA, Meltzer HY. Abnormal serotonergic stimulation of cortisol production in obstructive sleep apnea. Am J Respir Crit Care Med 1995; 152(1):186-92.

21. Besemer F, Pereira AM, Smit JW. Alcohol-induced Cushing syndrome. Hypercortisolism caused by alcohol abuse. Neth J Med 2011; 69(7):318-23. 